International Journal of Current Advanced Research

ISSN: O: 2319-6475, ISSN: P: 2319 - 6505, Impact Factor: SJIF: 5.995

Available Online at www.journalijcar.org

Volume 6; Issue 3; May 2017; Page No. 3985-3988

DOI: http://dx.doi.org/10.24327/ijcar.2017.3988.0412

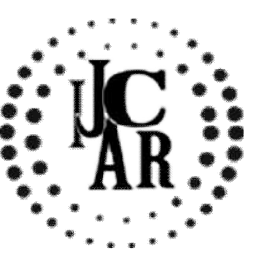

Research Article

\title{
STUDY OF ROSTRUM AND ANTENNA MALE FEMALE AND ALL INSTARS OF CHRYSOCORIS STOLLI WOLF (HETEROPTERA -PENTATOMIDAE -SCUTELLERANE)
}

\section{Sehgal P .K}

Department of Zoology/Entomology Dolphin (P.G) Institutes of Biomedical \& Natural Sciences Manduwala Chakrata Road Dehradun Uttarakhand Pin 248007

\section{A R T I C L E I N F O}

Article History:

$\operatorname{XXXXXXXXX}$

\section{Key words:}

Rostrum Antennae Chrysocoris stolli adults and instars

\begin{abstract}
A B S T R A C T
Insecta is the largest class of phylum arthropoda and members of this class are characterized by the presence of three pairs of legs; hence, called Hexapoda, Besides, these tracheate organism have usually one or two pairs of wings. Insects always have been associated with mankind in one way or the other as some of them are beneficial other are pests of crops and house hold articles. Chrysocoris stolli Wolf (Heteroptera- PentatomidaeScutellerinae) is a phytosuecivorous bug, which infests Cassia occidentalies, Croton sparisiflorum, Pennisetum typhoides, (Bajra) and Litchi chinensis at Saharanpur in good number and by its desapping habit causes considerable loss to these plants of economic value.

Male and female Chrysocoris stolli can be identified with their dimorphic characters presented in table (1) rostrum and antennae. Instars of Chrysocoris stolli can be identified with their dimorphic characters presented in table (2) rostrum and antennae. All figers and table attached in this result.
\end{abstract}

Copyright $\mathbb{C} 2017$ Sehgal P.K. This is an open access article distributed under the Creative Commons Attribution License, which permits unrestricted use, distribution, and reproduction in any medium, provided the original work is properly cited.

\section{INTRODUCTION}

Male and female Chrysocoris stolli can be identified with their dimorphic characters presented in (table-1). The antennae are dark brown with apical first and second segments and fourth segment light brown basally. First and second segments have larger and less dense punctuations while third and fourth antenna segments have small but dense punctuations giving brown, black appearance to the antenna (Fig-1). Comparative length of antenna segments is presented in table-1. Rostrum of male extends upto 5th and 6thabdominal sternite medially. The rostrum of male is brown with dark brown punctuations. It measures 6.2 to $6.8 \mathrm{~mm}$ in length with an average of $6.9 \mathrm{~mm}$ in male while in female it ranges from6.9 to $7.3 \mathrm{~mm}$ in length with an average of 7.2 $\mathrm{mm}$. Infemale rostrum generally extends upto 6th abdominal sternite.Comparative length of rostral segments is given in .verage width in between the eyes is calculated $1.2 \mathrm{~mm}$ and across the eyes $1.5 \mathrm{~mm}$. Antennae is four segmented which has brown scape and pedicel and brown black first and second flagellar segments. Terminal lower half segment is brown and upper half brown black and it is clavate in shape (Fig-2A). However, pedicel and first flagellar segment are not clearly demarcate. Hence, this segment is hereby, given name as pedicel + flagellum first. This condition occurs in all the nymphal instars but in adults these segments are separate.

\section{*Corresponding author: Sehgal P.K}

Department of Zoology/Entomology Dolphin (P.G)

Institutes of Biomedical \& Natural Sciences Manduwala

Chakrata Road Dehradun Uttarakhand Pin 248007
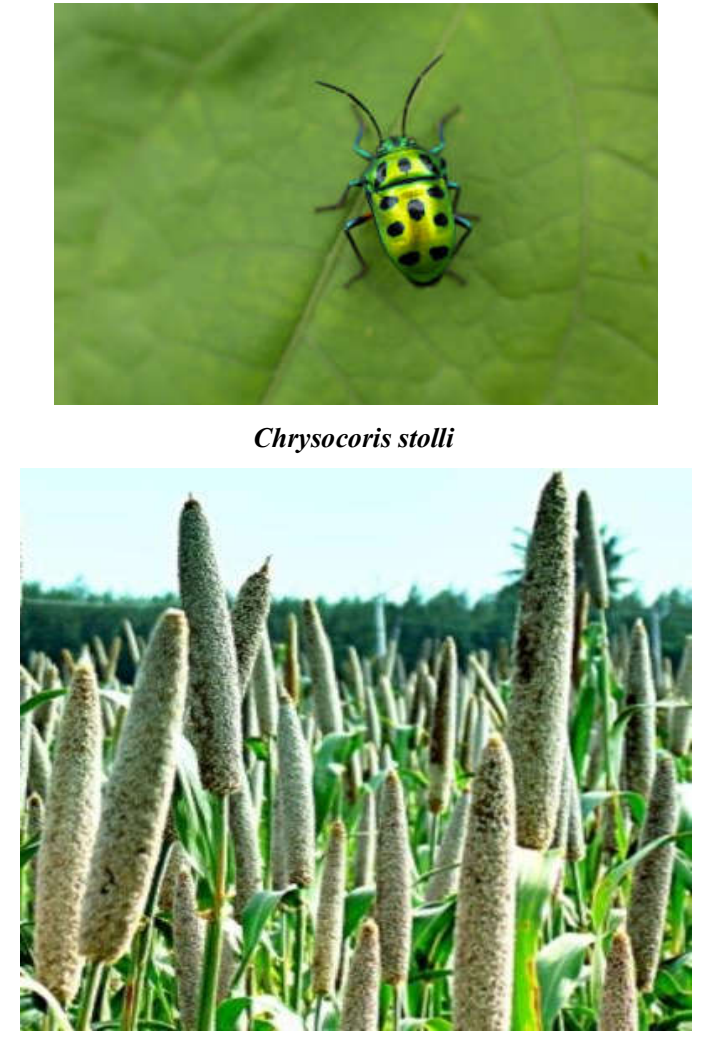

Food Plant of Chrysocoris Stolli 
The comparative length of antennal segments are scape 0.1 , pedicel + flagellum Ist $0.4 \mathrm{~mm}$, second flagellar segment 0.6 $\mathrm{mm}$, flagellum IIIrd segment $0.5 \mathrm{~mm}$ and total average length is $1.6 \mathrm{~mm}$ table-2.Attached all instars average with in the results.

\section{MATERIALS AND METHODS}

The present study deals with Chrysocoris stolli, a pest of Cassia occidentalies, Croton and Bajra and Litchi etc. Regarding this, the method of collection of bugs, biology, ecology, population dynamics, studies, rearing techniques and mounting methods are described here-A. Rearing of Chrysocoris stolli: For the study purpose, district Saharanpur was divided in 5 regions, in, Saharanpur proper, Nakur, Behat, Sarsawa and Nagal. Plantsware selected randomly in these regions and bugs were pickedup from Cassia occidentalies and Croton sparisiflorum and Bajra by hand picking method. In this experiment various shades of lights, viz;- red, blue, green, yellow and orange wear taken into consideration by using zero watt bulbs for attraction of bugs. For this purpose a big cage of the size $(60 \times 40 \times 30 \times \mathrm{cm})$ was taken and it was divided into six compartments leaving a small gap $\left(2 \frac{1}{2} \times 2 \frac{1}{2} \mathrm{~cm}\right)$ in each septum toward lower side. In this way all these six chambers were internally connected to each other so that bugs may move freely in each one without any interference. Now, in each chamber zero watt bulb of various shades of light, viz;-red, green,blue, yellow and orange were provided except a central chamber which was kept dark. In this chamber bugs were released and the bulbs were switched on during the night and observations wererecorded. It was noticed that not even a single bug moved to other lighted chambers from central dark one. To ascertain further, 10 bugs were released in each chamber except central

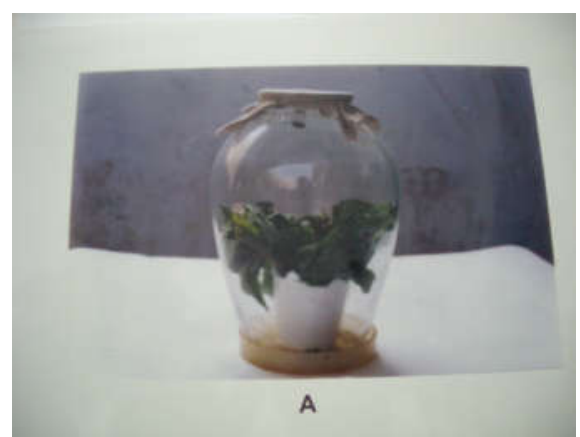

Hurricane glass lantern chimney use of rearing C.stolli

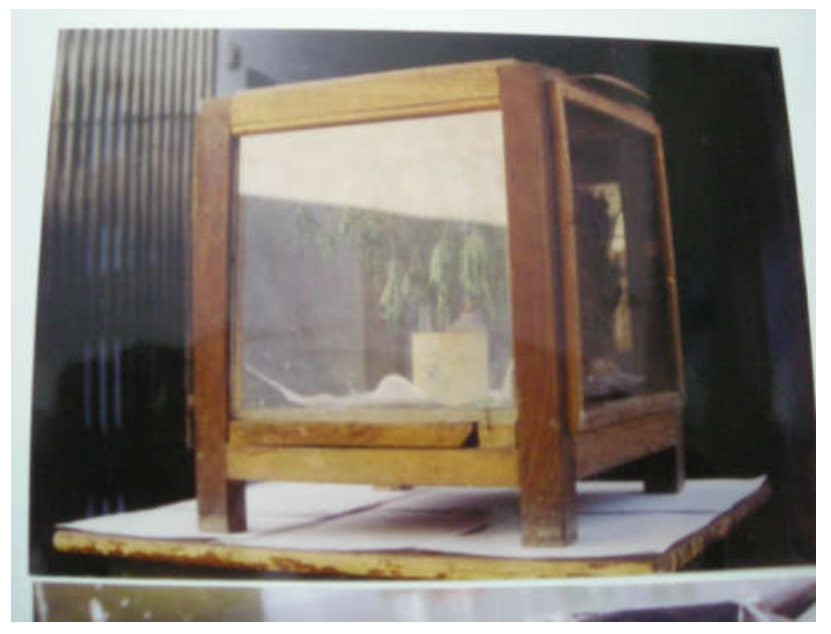

Wooden wire gauage cage use for rearing C.stolli dark one and the bulbs were lighted. It was observed that the bugs migrated to darker chamber within half an hour. This indicates negative attitude of the bug towards light.

\section{RESULTS}

Male and female Chrysocoris stolli can be identified with their dimorphic characters presented in table-1. Antennal length of male bug ranges from $8.3 \mathrm{~mm}$ to $8.9 \mathrm{~mm}$ with an average of $8.8 \mathrm{~mm}$ while in female it ranges from 8.9 to 9.2 $\mathrm{mm}$ with an average of $9.0 \mathrm{~mm}$ table -2 . The antennae are dark brown with apical firstand second segments and fourth segment light brown basally. First and second segments have larger and less dense punctuations while third and fourth antennal segments have small but dense punctuations giving brown, black appearance to the antenna (Fig-2). Comparative length of antennal segments ispresented in table-1. Rostrum of male extends upto 5th and 6thabdominal sternite medially. The rostrum of male is brown withdark brown punctuations. It measures 6.2 to $6.8 \mathrm{~mm}$ in lengthwith an average of $6.9 \mathrm{~mm}$ in male while in female it ranges from6.9 to $7.3 \mathrm{~mm}$ in length with an average of $7.2 \mathrm{~mm}$ (Table-1). Infemale rostrum generally extends upto 6th abdominal sternite.Comparative length of rostral segments is given in table-1.Pronotum is metallic greenish yellow with black spots. Its lengthin male range from 3.3 to $3.6 \mathrm{~mm}$ with an average of $3.4 \mathrm{mmwhile}$ in female it measures 3.4 to $3.7 \mathrm{~mm}$ in length, averagebeing 3.5 $\mathrm{mm}$. The width of male pronotum is 1.5 to 1.63 mmwith an average of $1.62 \mathrm{~mm}$. Pronotum of female ranges from 1.66 to $1.73 \mathrm{~mm}$ in width, average being $1.69 \mathrm{~mm}$. Mesothoraxbears dense punctuations in male and less dense in female.

First instar Antennae is four segmented which has brown scape and pedicel and brown black first and second flagellar segments. Terminal lower half segment is brown and upper half brown black and it is clavate in shape (Fig-2. However, pedicel and first flagellar segment are not clearly demarcate. Hence, this segment is hereby, given name as pedicel + flagellum first. This condition occurs in all the nymphal instars but in adults these segments are separate. The comparative length of antennal segments are scape 0.1 , pedicel + flagellum Ist $0.4 \mathrm{~mm}$, second flagellar segment 0.6 $\mathrm{mm}$, flagellum IIIrd segment $0.5 \mathrm{~mm}$ and total average length is $1.6 \mathrm{~mm}$.

Second instars antenna bears scape, pedical, flagellum, flagellum IInd and flagellum IIIrd. The terminal segment is clavate (Fig-2B). Total length of antenna is $2.4 \mathrm{~mm}$ and comparative length of its segments are - scape $0.2 \mathrm{~mm}$, pedicel + flagellum first $0.4 \mathrm{~mm}$, flagellum second $0.6 \mathrm{~mm}$, and flagellum third $1.2 \mathrm{~mm}$ (Table-1). Like first instar, pronotum, mesonotum and metanotumare distinctly marked. Wing buds are not prominently marked. Three dorsal abdominal scent glands are now more prominent withdark punctuation at the base of first abdominal scent gland and semicircular punctuations at second and third abdominal scentglands. Rostrum is brown, four segmented with dark brown second, third and forth rostral segments. Tip of fourth rostral segment is black with sensory hairs (Fig-2b). In first rostralsegment, maxillary and mandibular styletes can be differentiatedand they unite at the base of first rostral segment. In further rostralsegments they lies in the middle of rostrum in the rostral groove.Rostrum measures $2.3 \mathrm{~mm}$ in length and comparative length of itssegments are, first 
segments $0.2 \mathrm{~mm}$, second $0.5 \mathrm{~mm}$, third $0.3 \mathrm{~mm}$, and fourth $1.3 \mathrm{~mm}$ table-20.Legs are moderately sized with hairy setae on distal tibia as wellas on tarsi (Fig-3).

Third instar Antenna is like preceding instars (Fig-2C). It measure $4.2 \mathrm{~mm}$ in length and comparative length of itssegments are-scape, $1.0 \mathrm{~mm}$, pedicel and first flagellum 0.8 mm,flagellum IInd 1.1 and flagellum IIIrd $1.3 \mathrm{~mm}$ table-19. Small wingbuds start appearing. Abdominal scent glands are like precedinginstars except bigger $n$ size. Rostrum is brown and foursegmented. The fourth half segment is brown and lower half isbrown black having a tuft of sensory setae on its tip (Fig-2C). Rostrum measures $3.9 \mathrm{~mm}$ in length and comparative length of itssegments are first $0.5 \mathrm{~mm}$, second $0.7 \mathrm{~mm}$, third $0.6 \mathrm{~mm}$ and fourth0.9 $\mathrm{mm}$.

Fourth instar Antenna (Fig-2D) measures $6.2 \mathrm{~mm}$ in length and comparative length of its segments are-scape $1.3 \mathrm{~mm}$, pedicel + flagellum I, $1.4 \mathrm{~mm}$, second flagellum segment 1.5 $\mathrm{mm}$ and third flagellum segment $2.0 \mathrm{~mm}$. Rostrum is brown black four segmented (Fig-2D). Thefourth lower half rostral segment is dark black and a tuft of sensorysetae on it tip in present. Rostrum measures $5.2 \mathrm{~mm}$ in length and comparative length of its segments are-first $0.7 \mathrm{~mm}$, second $1.0 \mathrm{~mm}$, third $1.5 \mathrm{~mm}$ and fourth $2.0 \mathrm{~mm}$ black brown andlast segment also black brown with upper half light brownequipped with sensory setae. Antenna measures $7.1 \mathrm{~mm}$ in length and comparative length of its segments are-scape $1.3 \mathrm{~mm}$, pedicel+ flagellum first $1.4 \mathrm{~mm}$, second flagellum $1.9 \mathrm{~mm}$ and thirdsegment is $2.5 \mathrm{~mm}$.

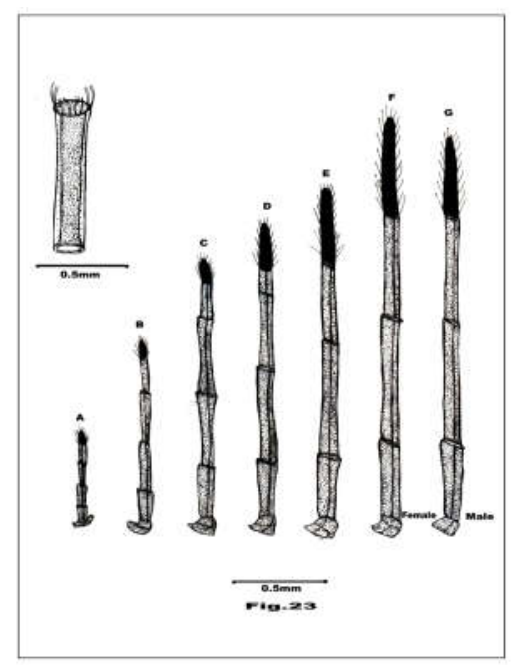

Fig. 1,2,3,4,5 A,B,C.D,E Rostrum of male and female C.stolli and all nymphs

Table 1 Average comparative length of antennal segment of various instars and adults C.stolli (in mm).

\begin{tabular}{|c|c|c|c|c|c|}
\hline Particulars & Scape & Pedical + Flagellum I & Flagellum II & Flagellum III & Total Length \\
\hline Ist Instar & 0.1 & 0.4 & 0.6 & 0.5 & 1.6 \\
\hline IInd Instar & 0.2 & 0.4 & 0.6 & 1.2 & 2.4 \\
\hline IIIrd Instar & 1.0 & 0.8 & 1.1 & 1.3 & 4.2 \\
\hline IVth Instar & 1.3 & 1.4 & 1.5 & 2.0 & 6.2 \\
\hline Vth Instar & 1.3 & 1.4 & 1.9 & 2.5 & 7.1 \\
\hline Malo & 14 & F. $L_{1}$ & F. $\mathrm{L}_{2}$ & F. $L_{3}$ & Total length \\
\hline Male & 1.4 & 1.7 & 2.5 & 3.0 & 8.8 \\
\hline Female & 1.4 & 1.7 & 2.7 & 3.0 & 9.0 \\
\hline
\end{tabular}

\section{Average has been taken of 100 observations}

Table 2 Comparative length (in $\mathrm{mm}$ ) of Various Rostral Segments of Various instars and adults of C.stolli.

\begin{tabular}{cccccc}
\hline Particular & I & II & III & IV & Total length \\
\hline Ist instar & 0.2 & 0.5 & 0.3 & 0.2 & 1.2 \\
IInd instar & 0.2 & 0.5 & 0.3 & 1.3 & 2.3 \\
IIIrd instar & 0.5 & 0.7 & 0.6 & 1.9 & 3.9 \\
IVth instar & 0.7 & 1.0 & 1.5 & 2.0 & 5.2 \\
Vth instar & 0.7 & 1.2 & 1.5 & 2.5 & 5.9 \\
Male & 1.0 & 1.3 & 1.8 & 2.8 & 6.9 \\
Female & 1.0 & 1.5 & 1.9 & 2.8 & 7.2 \\
\hline
\end{tabular}

Average has been taken for 100 observations

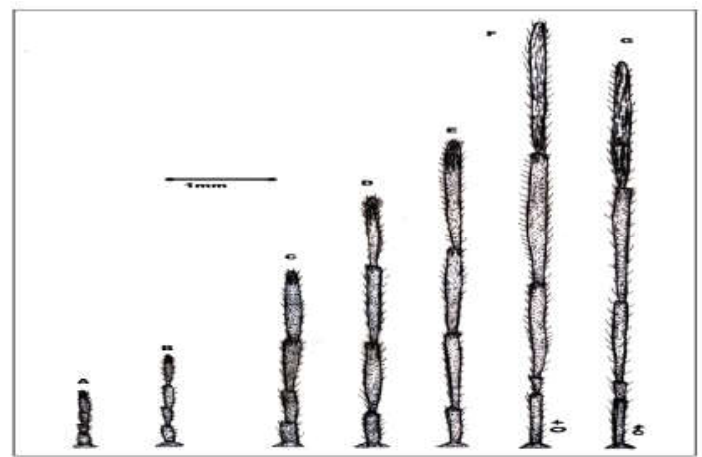

Fig. 1,2,3,4,5 A,B,C.D,E Antenna of male and female C.stolli and all nymphs

Fith instar Antenna (Fig-2E) has brown black scape, dark black pedicel +first flagellum and second flageller segments is
Total length of antenna is $7.1 \mathrm{~mm}$ Rostrum is four segmented reaching upto anterior partof third abdominal segment (Fig2E). It measures $5.9 \mathrm{~mm}$ length and comparative length of its segments are-first $0.7 \mathrm{~mm}$, second $1.2 \mathrm{~mm}$, third segment 1.5 $\mathrm{mm}$ and fourth segment $2.5 \mathrm{~mm}$.

\section{References}

1. Sehgal P.K and Dhiman S.C (2016) Description of Nymphal Instars of Chrysocoris stolli Wolf (Heteroptera-Pentatomida -Scutellerinae) International Journal of Science and Research (IJSR). Paper ID: NOV161062. International Journal of Science and Research (IJSR). Volume 5 Issue 2, February 2016.p.723-729.

2. Sehgal P.K and Dhiman S.C (2015). Study Of Population Dynamics of Chrysocoris Stolli Wolf (Heteroptera Pentatomidae Scutellerinae). International Journal of Pharma and Bio Sciences. Int J Pharm Bio Sci 2016 Jan; 7(1): (B).

3. Sehgal P.K and Dhiman S.C (2015).Effect of temperature and relative humidity on the occurrence of Chrysocoris stolli wolf (Heteroptera_Pentatomidae Scutellerinae) a potential bio control agent of Cassiao ccidentalies. European Journal of Biotechnology and Bio science.. Volume 3.Issue 4, 14-18 April 2015.

4. Kumar P and Dhiman.S.C. (2013), Oviposition fecundity and egg structure Chrysocoris stolli (heteroptera -pentatomidae-scutellerene). International 
journals of zoology and research. ISSN 2278-8816 (Vol. 3, Issue 1 Mar, 27 - 34).

5. Kumar. P. \& Dhiman S.C. (2013, Chrysocoris stolli Wolf, A Sap Feeder Pentatomidae Bug on the Weed in North Western Districts of Uttar Pradesh. IJASR, 06/2013; 3(2):89-92.

6. Dhiman S.C. and Kumar. P., 2005. Food plants and seasonal occurrence of Chrysocoris stolli Wolf. (Heteroptera - Pentatomidae - Scutellerinae). VI National symposium on Indian Entomology, Productivity and Health (A silver jubilee celebration), October 2- 4, 2005. Abstract 70; page 60. held at Haridwar by the Uttar Pradesh Zoological Society Muzaffarnagar 251001 (India).

7. Dhiman, S.C. and Kumar, P, 2006. Oviposition, fecundity and egg structure of Chrysocoris stolli Wolf. (Heteroptera - Pentatomidae - Scutellerinae). National symposium on Role of Applied Zoology in food Production and Human Health. (A Golden jubilee celebration) 23rd and 24th December 2006, Abstract IP 10; page 43. held at Department of Zoology M.S. (P.G.) College, Saharanpur, India.

8. Dhiman S.C. and Kumar P, 2007a. Some ethological aspect of Chrysocoris stolli Wolf. (HeteropteraPentatomiae-Scutellernae). AZRA, National conference on Applied zoology and sutainable development 13th - 14th July 2007 held at Indian Institute of Chemical Technology, Hydrabad. 500007. India, Abstract No. 018 page, 32.
9. Dhiman, S.C. and Kumar. P, 2007b. Copulatery behaviour of Chrysocoris stolli Wolf. (HepteropteraPentatomid-Scutellerinae). A polyphagous pest. National Seminar on threat Global warming to global warming (Sponsored by U.G.C. and C.S.I.R.). 31-0307. Abstract 28 page 81-82. held at department of Zoology K.L.D.A.V. (P.G.) College, Roorkee, India (U.K.).

10. Dhiman, S.C. and Kumar, P. 2007c. Biocontrol agent of Chrysocoris stolil Wolf and their biocont efficacy National seminar on Ailing earth and health Threats. (sponsared by U.G.C. and U.P.C.S.T.) 19th and 20th December 2007. Abstract No. 34; page 89 held at department of Zoology D.N. (P.G.) College (B++ NAAC Accredited) Meerut (Uttar Pradesh).

11. Dhiman, S.C. and Kumar, P. 2008d. Chrysocoris stolli Wolf, a sap feeder Pentatomidae bug on the weed in North western district of Uttar Pradesh. Biennial conference on Weed Management in modern Agriculture: Emerging challenges and opportunities 27-28 February, 2008. Abstracts No. P, 172, Page 214, held at National Research Centre for Weed Science, Jabalpur (M.P.), Rajendra Agricultural University, Pusa (Bihar).

12. Kumar. P., 2008.Biology, Ecology and Population dynamics of Chrysocoris stolli Wolf (Heteroptera Pentatomidae Scutellerinae) $\mathrm{PhD}$ thesis (unpublished) submitted to C.C.S. University Meerut page- 181 .

13. Kumar.P and Dhiman S.C. (2013). Research journals of pharmaceutical. Biological and chemical sciences. ISSN: 0975-8585 (Vol. 4 Issue 1, Page no .958).

\section{How to cite this article:}

Sehgal P .K (2017) 'Study Of Rostrum And Antenna Male Female And All Instars Of Chrysocoris Stolli Wolf (Heteroptera Pentatomidae -Scutellerane)', International Journal of Current Advanced Research, 06(05), pp. 3985-3988.

DOI: http://dx.doi.org/10.24327/ijcar.2017.3988.0412 